\title{
Synchrotron-based far-infrared spectroscopy of nickel tungstate
}

\author{
A. Kalinko ${ }^{1,2}$, A. Kuzmin ${ }^{1}$, P. Roy ${ }^{3}$, and R.A. Evarestov ${ }^{4}$ \\ ${ }^{1}$ Institute of Solid State Physics, University of Latvia, 8 Kengaraga Str., Riga LV-1063, Latvia \\ E-mail: a.kuzmin@cfi.lu.lv \\ ${ }^{2}$ Universität Paderborn, Naturwissenschaftliche Fakultät, Department Chemie \\ 100 Warburger Straße, Paderborn 33098, Germany \\ ${ }^{3}$ Synchrotron SOLEIL, l'Orme des Merisiers, Saint-Aubin, BP 48, Gif-sur-Yvette 91192, France \\ ${ }^{4}$ Department of Quantum Chemistry, St. Petersburg University \\ 26 Universitetskiy Prospekt, Stary Peterhof 198504, Russia
}

Received January 25, 2016, published online May 25, 2016

\begin{abstract}
Monoclinic antiferromagnetic $\mathrm{NiWO}_{4}$ was studied by far-infrared $\left(30-600 \mathrm{~cm}^{-1}\right)$ absorption spectroscopy in the temperature range of 5-300 $\mathrm{K}$ using the synchrotron radiation from SOLEIL source. Two isomorphous $\mathrm{CoWO}_{4}$ and $\mathrm{ZnWO}_{4}$ tungstates were investigated for comparison. The phonon contributions in the far-infrared range of tungstates were interpreted using the first-principles spin-polarized linear combination of atomic orbital calculations. No contributions from magnetic excitations were found in $\mathrm{NiWO}_{4}$ and $\mathrm{CoWO}_{4}$ below their Néel temperatures down to $5 \mathrm{~K}$.
\end{abstract}

PACS: 78.30.-j Infrared and Raman spectra;

71.15.-m Methods of electronic structure calculations.

Keywords: $\mathrm{NiWO}_{4}, \mathrm{CoWO}_{4}, \mathrm{ZnWO}_{4}$, infrared spectroscopy, first-principles calculations.

\section{Introduction}

Synchrotron light sources generate radiation with high flux and brilliance, which spans a wide range of electromagnetic spectrum, including its far-infrared part. Therefore, they are intensively used nowadays in infrared (IR) spectroscopy to probe vibrational properties of single crystalline [1,2], microcrystaline [2,3] and nanocrystalline materials [4-7]. Besides that infrared spectrum can contain information on magnetic excitations, which were observed, for example, in antiferromagnetic metal oxides as $\mathrm{CoO}$, $\mathrm{NiO}$ and solid solutions $\mathrm{Ni}_{c} \mathrm{Mg}_{1-c} \mathrm{O}$ and $\mathrm{Co}_{c} \mathrm{Mg}_{1-c} \mathrm{O}[2,8]$. Here synchrotron-based IR spectroscopy is applied to more complex binary metal oxide such as nickel tungstate $\left(\mathrm{NiWO}_{4}\right)$. Recent interests on $\mathrm{NiWO}_{4}$ have been stimulated by its applications as a catalyst $[9,10]$, in supercapacitors $[10,11]$ and light-controlled bipolar resistive switching devices [12] as well as by numerous possibilities to produce it in nanostructured form [13-20].

The vibrational properties of $\mathrm{NiWO}_{4}$ in the mid-infrared range $400-2000 \mathrm{~cm}^{-1}$ were studied previously in [21-23]. However, the magnetic structure of $\mathrm{NiWO}_{4}$ single crystal, having the Néel temperature $T_{N}=67 \mathrm{~K}$, was probed at $5 \mathrm{~K}$ by IR absorption spectroscopy only in Ref. 24 . Two antiferromagnetic resonance (AFMR) modes at 17.9 and $22.4 \mathrm{~cm}^{-1}$ were identified, and the third magnetic band was observed at $119 \mathrm{~cm}^{-1}$ : a value close to the doubled exchange energy [24]. It was found in [25] for cobalt $\left(\mathrm{CoF}_{2}, \mathrm{CoWO}_{4}\right)$ and manganese $\left(\mathrm{MnCO}_{3}, \mathrm{MnF}_{2}, \mathrm{RbMnF}_{3}, \mathrm{KMnF}_{3}\right)$ containing compounds that the maximum frequency in the spin-wave spectrum, estimated from the AFMR follows a linear dependence on the Néel temperature. Applying the same procedure to nickel compounds $\left(\mathrm{NiF}_{2}, \mathrm{KNiF}_{3}, \mathrm{NiO}\right)$, one can estimate a value for $\mathrm{NiWO}_{4}$ close to $108 \mathrm{~cm}^{-1}$, and thus the value of the doubled exchange energy $216 \mathrm{~cm}^{-1}$, which is nearly two times larger than proposed from AFMR measurements in [24].

In this study we have performed a temperature dependent $(5-300 \mathrm{~K})$ far-infrared $\left(30-600 \mathrm{~cm}^{-1}\right)$ study of polycrystalline $\mathrm{NiWO}_{4}$ tungstate using the synchrotron radiation from SOLEIL source [26]. A comparison with isostructural non-magnetic $\mathrm{ZnWO}_{4}$ and antiferromagnetic $\mathrm{CoWO}_{4}\left(T_{N}=55 \mathrm{~K}\right)$ compounds and first-principles linear combination of atomic orbital (LCAO) calculations was 
used to assign unambiguously the phonon bands with the aim to find possible magnetic excitations [24] and their temperature dependence in antiferromagnetic $\mathrm{NiWO}_{4}$ phase.

\section{Experimental and calculation details}

$\mathrm{AWO}_{4}(\mathrm{~A}=\mathrm{Co}, \mathrm{Ni}, \mathrm{Zn})$ polycrystalline powders were synthesized by co-precipitation technique [27] by mixing the aqueous solutions of $\mathrm{A}\left(\mathrm{NO}_{3}\right)_{2} \cdot 6 \mathrm{H}_{2} \mathrm{O}$ and $\mathrm{Na}_{2} \mathrm{WO}_{4} \cdot 2 \mathrm{H}_{2} \mathrm{O}$ salts and post-annealing the precipitate at $800-900^{\circ} \mathrm{C}$ for 8 hours. The phase purity of the samples was confirmed by $\mathrm{x}$-ray diffraction.

The infrared measurements were performed using the SOLEIL synchrotron light at AILES (advanced infrared line exploited for spectroscopy) beamline [26] in transmission mode. Far-IR spectra were recorded under vacuum in the range $30-600 \mathrm{~cm}^{-1}$ using a Bruker IFS $125 \mathrm{MR}$ Fourier transform spectrometer combined with a bolometer. The temperature range was 5-300 $\mathrm{K}$ with variable step. Isomorphous $\mathrm{ZnWO}_{4}$ and $\mathrm{CoWO}_{4}$ compounds were measured for comparison. Polycrystalline sample powders were milled in agate mortar, uniformly mixed with $100 \mathrm{mg}$ polyethylene powder and pressed into pellets.

To interpret infrared spectra, the first-principles LCAO calculations of the phonon frequencies in $\mathrm{ZnWO}_{4}$ and $\mathrm{CoWO}_{4}$ were performed using the direct (frozen phonon) method by the CRYSTAL09 code [28], whereas the results for $\mathrm{NiWO}_{4}$ were taken from our work [29]. The accuracy in the evaluation of the Coulomb and exchange series was controlled by a set of tolerances, set at $10^{-8}, 10^{-8}, 10^{-8}$, $10^{-8}, 10^{-16}$, to provide high numerical accuracy. The Monkhorst-Pack scheme [30] for $8 \times 8 \times 8 \mathrm{k}$-point mesh in

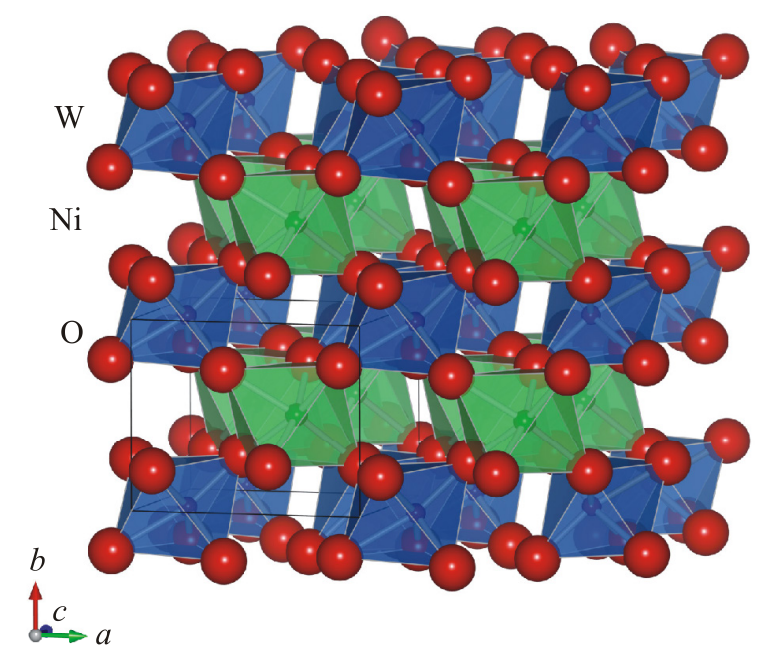

Fig. 1. (Color online) Crystal structure of woframite-type $\mathrm{NiWO}_{4}$. Crystallographic unit cell is indicated.

the Brillouin zone was applied. The SCF calculations were performed for hybrid Hartree-Fock (HF)/density functional (DFT) Hamiltonian (PBE0-type [31]) with 13\% of HF contribution, because they gave the best agreement with the experimental phonon frequencies of $\mathrm{NiWO}_{4}$ [29]. More details on the calculations can be found in Ref. 32 .

\section{Results and discussion}

Nickel tungstate has monoclinic wolframite-type structure (Fig. 1) with two formula units per unit cell (space group $P 2 / c$ (13)). It is build up from $\mathrm{NiO}_{6}$ and $\mathrm{WO}_{6}$ octahedra joined by the edges, which form zig-zag chains along the $c$ axis [33]. At ambient conditions $\mathrm{NiWO}_{4}$ exists

Table 1. Frequencies and intensities of infrared active modes in $\mathrm{AWO}_{4}(\mathrm{~A}=\mathrm{Co}, \mathrm{Ni}, \mathrm{Zn})$ calculated from first-principles using the LCAO method with hybrid DFT/HF functional PBE0-13\%

\begin{tabular}{|c|c|c|c|c|c|}
\hline \multicolumn{2}{|c|}{$\mathrm{NiWO}_{4}$} & \multicolumn{2}{|c|}{$\mathrm{CoWO}_{4}$} & \multicolumn{2}{|c|}{$\mathrm{ZnWO}_{4}$} \\
\hline Frequency, $\mathrm{cm}^{-1}$ & Intensity & Frequency, $\mathrm{cm}^{-1}$ & Intensity & Frequency, $\mathrm{cm}^{-1}$ & Intensity \\
\hline 187 & 2.54 & 170 & 2.26 & 141 & 12.11 \\
\hline 219 & 8.83 & 199 & 10.47 & 151 & 10.95 \\
\hline 226 & 3.49 & 208 & 7.03 & 174 & 10.74 \\
\hline 267 & 34.07 & 250 & 22.61 & 247 & 35.82 \\
\hline 280 & 20.36 & 271 & 40.53 & 262 & 33.68 \\
\hline 313 & 35.75 & 301 & 24.95 & 279 & 0.99 \\
\hline 331 & 30.02 & 326 & 24.23 & 320 & 9.58 \\
\hline 349 & 8.41 & 344 & 6.88 & 340 & 16.18 \\
\hline 446 & 8.76 & 434 & 5.15 & 431 & 4.16 \\
\hline 457 & 8.95 & 444 & 18.38 & 458 & 8.02 \\
\hline 514 & 19.80 & 505 & 23.89 & 516 & 18.54 \\
\hline 560 & 97.25 & 535 & 98.43 & 554 & 100.00 \\
\hline 677 & 45.47 & 651 & 51.43 & 661 & 46.17 \\
\hline 745 & 100.00 & 742 & 100.00 & 762 & 83.65 \\
\hline 862 & 14.69 & 854 & 14.40 & 866 & 12.67 \\
\hline
\end{tabular}




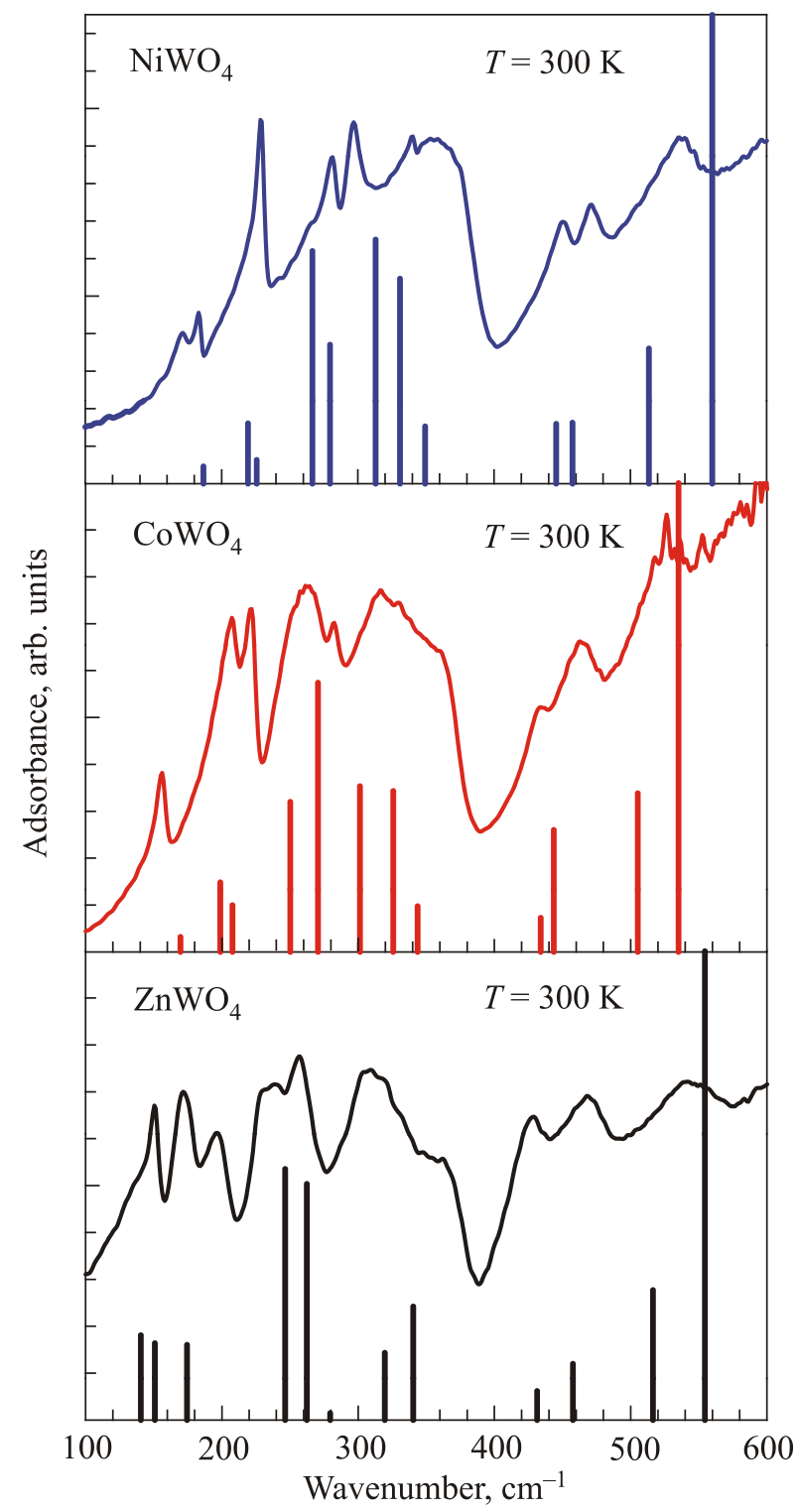

Fig. 2. (Color online) Far-IR absorption spectra measured at $T=$ $=300 \mathrm{~K}$ for isostructural woframite-type compounds $\mathrm{AWO}_{4}$ $(\mathrm{A}=\mathrm{Co}, \mathrm{Ni}, \mathrm{Zn})$. Spectra are vertically shifted for clarity. Vertical bars indicate the phonon modes from the first-principles LCAO calculations.

in the paramagnetic phase, while below the Néel temperature $T_{N}=67 \mathrm{~K}$ the spins on nickel ions order antiferromagnetically [34] leading to the doubling of the crystallographic unit cell along the $a$ axis.

The atomic and electronic structures as well as phonon properties in $\Gamma$-point of the Brillouin zone of $\mathrm{NiWO}_{4}$ were studied in details by us using the first-principles spinpolarized LCAO calculations based on the hybrid HF/DFT scheme [29]. The obtained results were in good agreement with the available experimental data. In particular, we found that a correct account for the magnetic ordering gives also the best results for the vibration frequencies probed by Raman spectroscopy [29]. Therefore, we have
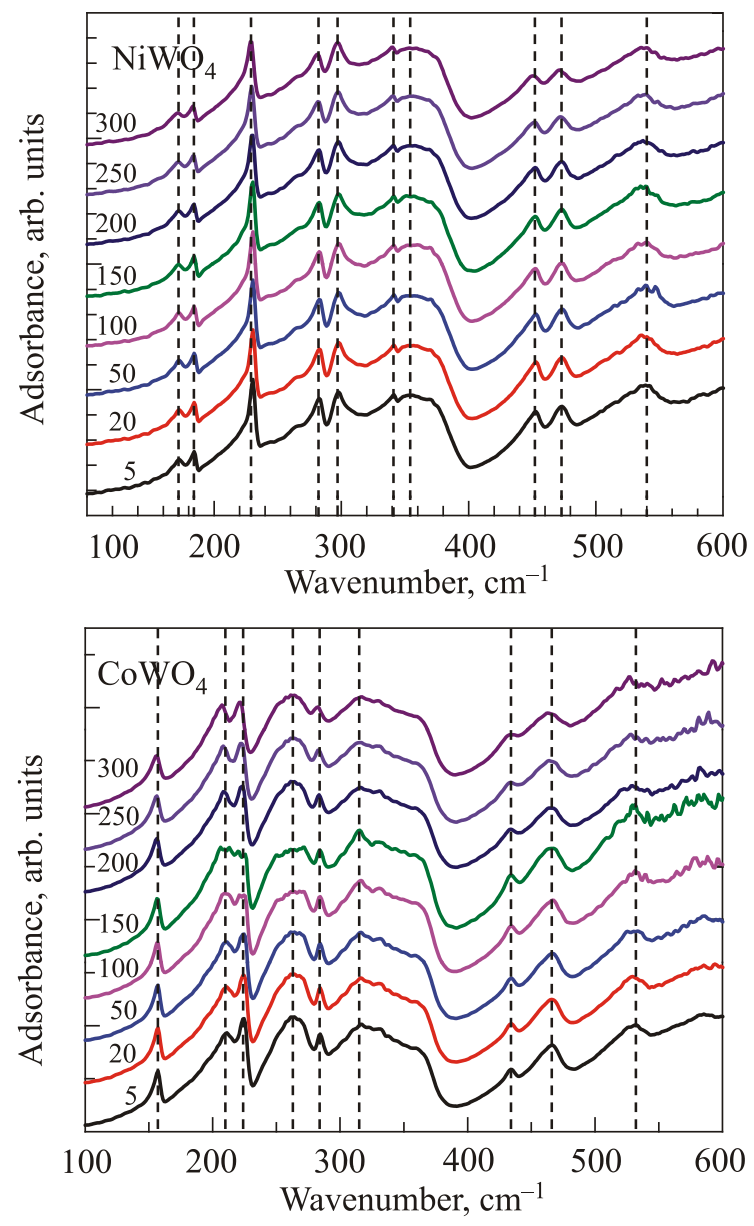

Fig. 3. (Color online) Temperature dependent (5-300 K) far-IR absorption spectra of $\mathrm{NiWO}_{4}$. The positions of vibrational bands are indicated by vertical dashed lines.

utilized similar approach to calculate phonon modes in $\mathrm{CoWO}_{4}$ with the Néel temperature $T_{N}=55 \mathrm{~K}$ [35], whereas non-magnetic LCAO calculations were performed for $\mathrm{ZnWO}_{4}$.

The group theory predicts 36 lattice modes for space group $P 2 / c$ : 3 acoustic modes, 18 Raman active modes and 15 IR active modes. Twelve IR active modes $(5 \mathrm{Au}+7 \mathrm{Bu})$ are observed experimentally in isostructural $\mathrm{NiWO}_{4}$, $\mathrm{CoWO}_{4}$ and $\mathrm{ZnWO}_{4}$ below $600 \mathrm{~cm}^{-1}$ in Fig. 2 and are compared with the theoretical ones (vertical bars) obtained from the first-principles spin-polarized LCAO calculations $[29,36]$. The position and the height of the bars indicate calculated mode frequency and intensity, respectively. Full set of calculated frequencies and intensities for all IRactive modes in tungstates is given in Table 1. While one can notice a good qualitative agreement between the theory and the experiment in Fig. 2, the absolute values of vibrational frequencies can differ by $\pm 25 \mathrm{~cm}^{-1}$.

The vibrational properties of $\mathrm{NiWO}_{4}$ in the midinfrared range $400-2000 \mathrm{~cm}^{-1}$ were studied previously in [21-23]. Our temperature dependence of the far-IR absorption spectrum of $\mathrm{NiWO}_{4}$ is shown in Fig. 3 in comparison 
with the results for $\mathrm{CoWO}_{4}$. Upon temperature increase from $5 \mathrm{~K}$ to $300 \mathrm{~K}$, the only noticeable changes are observed in the positions of vibrational bands. They shift slightly due to lattice expansion and anharmonic effects that reflects the rigidity of the tungstate lattice. No new bands are observed in Fig. 3 that confirms the absence of any structural phase transition in $\mathrm{NiWO}_{4}$ and $\mathrm{CoWO}_{4}$ at atmospheric pressure from 5 to $300 \mathrm{~K}$. Finally, we did not observe in our polycrystalline $\mathrm{NiWO}_{4}$ sample any absorption related to magnetic excitations at $119 \mathrm{~cm}^{-1}$, which was found previously in [24]. Also no AFMR modes, observed in [24] at 67 and $79.3 \mathrm{~cm}^{-1}$, were found in IRspectra of $\mathrm{CoWO}_{4}$.

At the end, we note that this article is another example of the use of synchrotron radiation, which we have used in our previous papers for study of the VUV spectroscopic properties of $\mathrm{NiWO}_{4}[37,38]$.

\section{Conclusions}

Temperature dependent (10-300 K) far-infrared (30$600 \mathrm{~cm}^{-1}$ ) study of polycrystalline monoclinic $\mathrm{NiWO}_{4}$ was performed in comparison with isomorphous $\mathrm{CoWO}_{4}$ and $\mathrm{ZnWO}_{4}$ tungstates using the synchrotron radiation from SOLEIL source. The phonon contributions into farIR absorption spectra of tungstates were successfully interpreted using the first-principles spin-polarized LCAO calculations. Weak temperature dependence of the far-IR absorption in $\mathrm{NiWO}_{4}$ and $\mathrm{CoWO}_{4}$ was found and attributed to the rigidity of their lattices. At the same time, no magnetic contributions were observed down to $5 \mathrm{~K}$ in both tungstates.

This work was supported by Latvian Science Council Grant No. 187/2012. The infrared measurements have been supported by synchrotron SOLEIL (Proposal 20110863).

1. I. Bolesta, S. Velgosh, Y. Datsiuk, I. Karbovnyk, V. Lesivtsiv, T. Kulay, A.I. Popov, S. Bellucci, M. Cestelli Guidi, and A. Marcelli, Radiat. Meas. 42, 851 (2007).

2. N. Mironova-Ulmane, U. Ulmanis, A. Kuzmin, I. Sildos, M. Pars, M. Cestelli Guidi, M. Piccinini, and A. Marcelli, Phys. Solid State 50, 1657 (2008).

3. I. Karbovnyk, S. Piskunov, I. Bolesta, S. Bellucci, M. Cestelli Guidi, M. Piccinini, E. Spohr, and A.I. Popov, Eur. Phys. J. B 70, 443 (2009).

4. C. Balasubramanian, S. Bellucci, G. Cinque, A. Marcelli, M. Cestelli Guidi, M. Piccinini, A. Popov, A. Soldatov, and P. Onorato, J. Phys.: Condens. Matter 18, S2095 (2006).

5. S. Bellucci, A.I. Popov, C. Balasubramanian, G. Cinque, A. Marcelli, I. Karbovnyk, V. Savchyn, and N. Krutyak, Radiat. Meas. 42, 708 (2007).

6. A. Voloshynovskii, P. Savchyn, I. Karbovnyk, S. Myagkota, M. Cestelli Guidi, M. Piccinini, and A.I. Popov, Solid State Commun. 149, 593 (2009).
7. P. Savchyn, I. Karbovnyk, V. Vistovskyy, A. Voloshinovskii, V. Pankratov, M. Cestelli Guidi, C. Mirri, O. Myahkota, A. Riabtseva, N. Mitina, A. Zaichenko, and A.I. Popov, J. Appl. Phys. 112, 124309 (2012).

8. N. Mironova-Ulmane, A. Kuzmin, M. Cestelli Guidi, M. Piccinini, and A. Marcelli, Phys. Status Solidi C 2, 704 (2005).

9. J.M. Quintana-Melgoza, J. Cruz-Reyes, and M. AvalosBorja, Mater. Lett. 47, 314 (2001).

10. U. Nithiyanantham, S.R. Ede, S. Anantharaj, and S. Kundu, Cryst. Growth Des. 15, 673 (2015).

11. L. Niu, Z. Li, Y. Xu, J. Sun, W. Hong, X. Liu, J. Wang, and S. Yang, ACS Appl. Mater. Interfaces 5, 8044 (2013).

12. B. Sun, W. Zhao, L. Wei, H. Li, and P. Chen, Chem. Commun. 50, 13142 (2014).

13. P.S. Pandey, N.S. Bhave, and R.B. Kharat, Electrochim. Acta 51, 4659 (2006).

14. Y. Bi, H. Nie, D. Li, S. Zeng, Q. Yang, and M. Li, Chem. Commun. 46, 7430 (2010).

15. A. Anspoks, A. Kalinko, J. Timoshenko, and A. Kuzmin, Solid State Commun. 183, 22 (2014).

16. Y. Jiang, B. Liu, Z. Zhai, X. Liu, B. Yang, L. Liu, and X. Jiang, Appl. Surf. Sci. 356, 273 (2015).

17. R. Karthiga, B. Kavitha, M. Rajarajan, and A. Suganthi, Mater. Sci. Semicond. Proc. 40, 123 (2015).

18. G. Nagaraju, R. Kakarla, S.M. Cha, and J.S. Yu, Nano Res. 8, 3749 (2015).

19. K.P.F. Siqueira and A. Dias, J. Nanopart. Res. 13, 5927 (2011).

20. Y. Wang and Y. Wang, Adv. Mater. Res. 311, 545 (2011).

21. M.N. Mancheva, R.S. Iordanova, D.G. Klissurski, G.T. Tyuliev, and B.N. Kunev, J. Phys. Chem. C 111, 1101 (2007).

22. A.L.M. de Oliveira, J.M. Ferreira, M.R.S. Silva, G.S. Braga, L.E.B. Soledade, M.A.M.M. Aldeiza, C.A. Paskocimas, S.J.G. Lima, E. Longo, A.G. de Souza, and I.M.G. dos Santos, Dyes Pigments 77, 210 (2008).

23. A.L.M. de Oliveira, J.M. Ferreira, M.R.S. Silva, S.C. de Souza, F.T.G. Vieira, E. Longo, A.G. Souza, and I.M.G. Santos, J. Therm. Anal. Calorim. 97, 167 (2009).

24. V. Eremenko, V. Naumenko, A. Zvyagin, and A. Maslennikov, IEEE T. Microw. Theory 22, 1069 (1974).

25. V.V. Eremenko and V.M. Naumenko, ZhETF Pis'ma 7, 416 (1968).

26. P. Roy, M. Rouzieres, Z. Qi, and O. Chubar, Infrared Phys. Techn. 49, 139 (2006).

27. A. Kalinko and A. Kuzmin, J. Lumin. 129, 1144 (2009).

28. R. Dovesi, V.R. Saunders, R. Roetti, R. Orlando, C.M. Zicovich-Wilson, F. Pascale , B. Civalleri, K. Doll, N.M. Harrison, I.J. Bush, P. D'Arco, and M. Llunell, CRYSTAL09 User's Manual, University of Torino (2009).

29. A. Kuzmin, A. Kalinko, and R.A. Evarestov, Centr. Eur. J. Phys. 9, 502 (2011).

30. H.J. Monkhorst and J.D. Pack, Phys. Rev. B 13, 5188 (1976).

31. J.P. Perdew, K. Burke, and M. Ernzerhof, Phys. Rev. Lett. 77, 3865 (1996). 
32. A. Kuzmin, A. Kalinko, and R.A. Evarestov, Acta Mater. 61, 371 (2013).

33. R.O. Keeling, Acta Crystallogr. 10, 209 (1957).

34. C.P. Landee and E.F. Westrum, J. Chem. Thermodyn. 8, 471 (1976).

35. H. Weitzel, Solid State Commun. 8, 2071 (1970).

36. A. Kalinko, A. Kuzmin, and R.A. Evarestov, Solid State Commun. 149, 425 (2009).
37. A. Kalinko, A. Kotlov, A. Kuzmin, A. Pankratov, A.I. Popov, and L. Shirmane, Centr. Eur. J. Phys. 9, 432 (2011).

38. A. Kuzmin, V. Pankratov, A. Kalinko, A. Kotlov, L. Shirmane, and A.I. Popov, Fiz. Nizk. Temp. 42, 694 (2016) [Low Temp. Phys. 42, No. 7 (2016)]. 